\title{
Pragmatics in Teacher Talk: The Case of Pre-Primary Education
}

\author{
Júlia Barón ${ }^{1}$, Helena Roquet ${ }^{1}$, Natalia Evnitskaya ${ }^{1} \&$ Noelia Navarro ${ }^{1}$ \\ ${ }^{1}$ Institute for Multilingualism, Department of Applied Linguistics, Universitat Internacional de Catalunya, Spain \\ Correspondence: Júlia Barón, Institute for Multilingualism, Department of Applied Linguistics, Universitat \\ Internacional de Catalunya, Josep Trueta s/n, 08195, Sant Cugat del Vallès, Barcelona, Spain.
}

Received: June 24, 2020

doi: $10.5539 /$ elt.v13n8p168
Accepted: July 24, 2020

Online Published: July 28, 2020

URL: https://doi.org/10.5539/elt.v13n8p168

\begin{abstract}
This study aims to explore how the speech act of requesting is performed in Catalan (L1), English (L1) and EFL classrooms by pre-primary teachers. The study examines transcripts of 40-minute video-recorded lessons (six in Catalan/L1, six in English/FL, and three in English/L1) collected in several pre-primary schools in Catalonia, Spain. Recall interviews with the teachers were also conducted in order to examine their perceptions of their pragmatic performances in the classroom. Results show that teachers predominantly use imperatives in the three groups (Catalan L1, English L1 and EFL); however, a wider variety of requesting strategies is used in the L1 lessons. The study concludes with reflections on the pedagogical implications of the findings and calls for the need to raise teachers' awareness about the effect their language use might have on the development of learners' pragmatic competence both in the L1 and the foreign language.
\end{abstract}

Keywords: pragmatics, requests, pragmatic socialization, teacher talk, input

\section{Introduction}

\subsection{Learning Pragmatics}

The study of pragmatics, "how-to-say-what-to-whom-when" (Bardovi-Harlig 2013: 68), in foreign and second language instructional contexts, has been a key issue in the field of second language acquisition (SLA) for the last few decades. The main aim has been to understand how learners acquire and develop the second language (L2) pragmatics, in order to find ways to teach pragmatics in classroom contexts. Both explicit and implicit instruction has been proved to have positive effects on L2 pragmatic learning, yet, with better results when explicit instruction is given, since learners seem to benefit from metapragmatic explanations (Alcón-Soler 2005; Taguchi 2015). Studies on both children and adults reveal certain differences in their learning process. Adults seem to have the advantage of being already pragmatically competent in their first language (L1); however, children need to develop their L1 pragmatic competence at the same time as they are learning the L2 pragmatics (Bialystok 1993). Nowadays, introducing foreign language (FL) learning at very early ages is becoming a more widespread practice, as is the case of Spain where children often start learning English as a foreign language (EFL) in pre-primary education (3-5 years old). It is, therefore, necessary to understand what pragmatic input such very young learners are exposed to in classroom contexts, in both their L1 and the L2. Such knowledge might help teachers develop pedagogical proposals aimed at teaching (both explicitly and implicitly) pragmatics in pre-primary education. The present study thus aims to further contribute to this area of inquiry.

\subsection{Pragmatics in Early L1 Language Acquisition}

Children are expected to be polite, or at least, they are constantly required to be polite by their parents and caregivers; for example, when they are given gifts or when they are asking for something, they are explicitly told to say 'thank you' or 'please' (Ladegaard 2004). As suggested by Greif and Gleason (1980), children aged 2-5 might produce polite formulas when parents are present, but they might not when being on their own. Therefore, it seems that parents, and probably adults in general, may play an important role in children's pragmatic learning. In fact, research on pragmatic socialization has studied how children "are socialized to use language in context in socially and culturally appropriate ways" (Blum-Kulka 1997: 3) which seems to involve both explicit and implicit learning processes. On the one hand, the process is explicit, when parents, caregivers, and teachers, that is, pragmatically competent members of the community, provide children with specific pragmatic formulas in given social situations, like 'say thank you'. On the other hand, the process can also be implicit when children are simply engaged in observing and interacting with more pragmatically competent members of the community 
in a more natural way (Ochs 1990; Li 2008). The notion of "pragmatic socialization" has been used, therefore, to explain how children learn both explicitly and implicitly the pragmatic norms of their L1. However, what happens in $\mathrm{L} 2$ acquisition?

\subsection{Pragmatics in EFL Contexts}

As research on formal instructional contexts has shown, there are certain factors that may hinder L2 pragmatic learning (see e.g. González-Lloret 2019). There seem to be several reasons behind it: first, textbooks provide low frequency of speech acts (Martínez-Flor \& Usó-Juan 2011); second, if present, pragmatic exchanges do not reflect real-life interactions (Martínez-Flor \& Fernández-Guerra 2002); and third, teacher talk often provides students with a rather limited variety of communicative situations and registers (Nikula 2002). All of this often results in the low range and variety of pragmatic strategies acquired by learners (Ellis 1992).

When examining the role of teacher talk, studies on L2 classroom interaction have commonly found a high presence of directness, a lack of politeness and an unequal distribution of power among speakers (Lörscher \& Schulze 1988; Falsgraf \& Majors 1995; Dalton-Puffer 2007). In addition, when comparing L1 and L2 classroom interaction, a wider pragmatic repertoire is found in the L1, compared to the L2, probably due to the teachers' and students' differential competence in both languages (Nikula 2002). However, studies on pragmatic socialization in L2 contexts have claimed that pragmatic learning can take place (both implicitly and explicitly) through classroom interaction, since teachers also represent and teach the pragmatic and social norms of the L2 (Nikula 2008; Ohta 2001; Tateyama 2019; Tateyama \& Kasper 2008). As claimed by Taguchi (2011), more studies, though, are needed to further examine how pragmatics is displayed in teacher talk in classroom contexts and how this can contribute to learners' pragmatic socialization in the L2.

\subsection{The Study of Requests}

Requests have been widely studied in the field of pragmatics, both in L1 and L2 performance and acquisition. Requests are a type of a directive speech act, which aims to get the interlocutor to do something (Searle 1969). This speech act has commonly been classified into direct and indirect. In direct requests, the literal meaning of the speech act can easily be understood, e.g. the use of imperatives. However, in indirect requests, the interlocutor has to infer the meaning conveyed in the act, for instance, by interpreting hints given by the speaker in expressions such as 'it is hot in here' (Clark 1979). All speakers, both native and non-native, use direct and indirect requests depending on the context and the degree of familiarity between the speakers. In addition, language and culture will also determine directness in requests. For example, even though English and Catalan are Western cultures, in Catalan the use of directness is more frequent than in English (O'Neil \& Casanovas 1997).

Regarding studies on L2 pragmatic development, findings have shown that the most common pattern of acquisition evolves from direct request use at early stages of acquisition, to more indirect requests at more advanced levels (see Kasper \& Rose 2002). Such pattern seems to be similar in L1 acquisition; Carrell (1981) found that in case of children (aged 4-7), their understanding of indirect requests improved as their age and language competence increased, as well as their understanding of a wider range of different request types. Similar findings were also found in Safont-Jordà (2013), in which a trilingual kid (Catalan-Spanish = languages spoken at home; English = formal instruction and playtime) showed development from direct to indirect requests in Catalan, Spanish and English (from 3 to 5 years old). This natural development from direct to indirect in pragmatics acquisition (both in the L1 and the L2) might also explain why teachers adapt the use of requests to the students' age and proficiency levels in classroom contexts. Our study thus aims to analyse how pre-primary teachers deal with pragmatics, more specifically with the use of requests in teacher talk. Therefore, the following research question has guided this study:

1. How are requests displayed by pre-primary teachers in L1 (Catalan/English) and EFL classrooms?

Based on the literature reviewed, we hypothesize that $\mathrm{L} 1$ teachers use a wider pragmatic request repertoire than L2 teachers but also that both L1 and L2 pre-primary teachers use more direct than indirect requests.

\section{Method}

\subsection{Participants and Context}

The data corpus consists of fifteen video-recordings of 40-minute pre-primary school lessons (grades P3, P4 and P5) (Note 1): six were in L1 Catalan (Group 1/G1), six in L2 English (Group 2/G2) and three in L1 English (Group 3/G3). The classroom recordings were made in three schools in Catalonia, Spain. Two of the schools were state schools in which the students and teachers are mostly Catalan/Spanish bilinguals. The third school was a private international school which followed an immersion program in English. The majority of students in 
this school were either native-speakers of English or bilinguals (English + another language).

Regarding the pre-primary teachers of the present study $(\mathrm{N}=12)$, they were teaching children aged 3-5. There were 11 female and 1 male teachers aged between 25 and 55. Regarding their L1 and language of instruction, six teachers were L1 Catalan speakers who taught their classes in Catalan (G1); three were L1 Catalan speakers who taught EFL (G2) and had a B2.2-C1 CEFR level (according to the Oxford Placement Test); and finally, three teachers were L1 English native-speakers (G3) who taught their classes in English.

\subsection{Data Collection}

Before starting the data collection both teachers and parents were asked for their consent to being recorded. All the video-recorded lessons had a similar structure and organization. Nine lessons (six L1 Catalan lessons and three EFL lessons) were the first classes in the morning and were organized as follows: the first part of the class was devoted to the 'morning routine' which consisted in teachers greeting the students and the students greeting each other, talking about the weather, identifying the day of the week or listening to songs related to these 'morning routine' activities. After that, the teachers set up an activity. As for the rest of lessons (three EFL lessons and three L1 English lessons), they started with the teacher greeting the students, and afterwards directly setting an activity.

Apart from the video-recorded classroom data, recall interviews with the teachers were conducted (see Appendix 1). In the recall interviews, teachers were first explained what pragmatics and pragmatic socialization were. Second, teachers were shown short vignettes taken from their video-recorded lessons to elicit reasons behind using different request types.

\subsection{Data Analysis and Measures}

This study follows a mixed-methods design. Once the classroom recordings were collected, all sessions were transcribed and analyzed using CLAN software. Afterwards, transcriptions were anonymised (teachers' and students' names). Using a qualitative approach to data, we examined the corpus data focusing on the requests performed by the teachers during the lessons. The findings on requests in the corpus data were then triangulated with the teachers' answers in the recall interviews.

Requests were analyzed following the already existing categorization by Blum-Kulka and Olshtain (1984), which was developed in the Cross-cultural Study of Speech Act Realization Patterns project (CCSARP), to code both English and Catalan data (see Appendix 2). Such categorization was used because previous studies have found that such request categories can also be identified in Catalan (Pérez i Parent 2002). However, the data of the present study provided requests that were not included in Blum-Kulka and Olshtain's categorization. Therefore, new categories needed to be created. The data were analysed and coded by two researchers. 95\% of agreement was reached, and for the remaining 5\%, discrepancies were discussed. Table 1 shows, first, the requests types that were identified in the data corpus from the present study (those marked with an * are the request types which were not present in Blum-Kulka and Olshtain's categorisation). Second, Table 1 provides examples from the lessons, together with the groups from where the examples were taken from.

Table 1. Request types and examples

\begin{tabular}{ll}
\hline Request types & Examples \\
\hline Imperatives & Sit down boys $(\mathrm{G} 2)$ \\
Imperatives with we * & We keep silence $(\mathrm{G} 1)$ \\
Let's... * & Let's be quiet $(\mathrm{G} 3)$ \\
Can you...? * & Can you sit? (G2) \\
Need statements * & Ineed you to look at the pictures $(\mathrm{G} 1)$ \\
Hints & We are a little bit louder here, no? (G2) \\
If-clauses requests* & If you play with the dool, you will give me the doll \\
Would & (G2) \\
Could & Would you like to tell her your name? (G3) \\
Why don't...? & Could you sit down?(G2) \\
\hline
\end{tabular}




\section{Results}

This section consists of two main parts. First, findings on the teachers' use of requests strategies, illustrated with examples from the data, are presented. This is done across the three groups (L1 Catalan lessons/G1, EFL lessons/G2, and L1 English lessons/G3), followed by a more detailed analysis for each group. Second, findings from the recall interviews with the teachers are also presented.

\subsection{Teachers' Use of Requests in Classrooms across the Three Groups}

Table 2 summarizes the total frequency of requests found in the three subcorpora, according to the categories explored. In general, teachers in the G2 group produced more requests (77) than teachers in the other two groups, as can bee seen in Table 2 .

Table 2. Frequency of requests across groups: tokens and \%

\begin{tabular}{|c|c|c|c|c|c|c|}
\hline \multirow[b]{2}{*}{ Imp } & \multicolumn{2}{|c|}{ G1 CAT-CAT } & \multicolumn{2}{|c|}{ G2 CAT-ENG } & \multicolumn{2}{|c|}{ G3 ENG-ENG } \\
\hline & 25 & $43.1 \%$ & 65 & $84.4 \%$ & 29 & $60.4 \%$ \\
\hline Imp_Imp & 4 & $6.9 \%$ & 0 & - & 0 & - \\
\hline We & 18 & $31.0 \%$ & 2 & $2.6 \%$ & 2 & $4.2 \%$ \\
\hline Let's & 3 & $5.2 \%$ & 0 & - & 1 & $2.1 \%$ \\
\hline Can you & 2 & $3.4 \%$ & 2 & $2.6 \%$ & 4 & $8.3 \%$ \\
\hline Need & 0 & - & 0 & - & 4 & $8.3 \%$ \\
\hline Hint & 6 & $10.3 \%$ & 2 & $2.6 \%$ & 3 & $6.3 \%$ \\
\hline If-clause & 0 & - & 6 & $7.8 \%$ & 1 & $2.1 \%$ \\
\hline Would & 0 & - & 0 & - & 1 & $2.1 \%$ \\
\hline Could & 0 & - & 0 & - & 1 & $2.1 \%$ \\
\hline Why don't & 0 & - & 0 & - & 2 & $4.2 \%$ \\
\hline TOTAL & 58 & 100 & 77 & 100 & 48 & 100 \\
\hline
\end{tabular}

Due to a small data sample for G3, Kruskal Wallis test for inter-group comparison was applied only to the data from G1 and G2. The results showed statistically significant differences for the use of imperative requests $(p=.006)$ and for requests with 'we' $(p=.007)$. As can be seen in Figure 1 below, imperative requests were the most commonly used strategy by the teachers in the three groups: $43 \%(\mathrm{G} 1), 84 \%(\mathrm{G} 2)$ and $61 \%(\mathrm{G} 3)$. As can be noticed, it is in G2, that is, the EFL lessons, though, in which imperative requests were used the most.

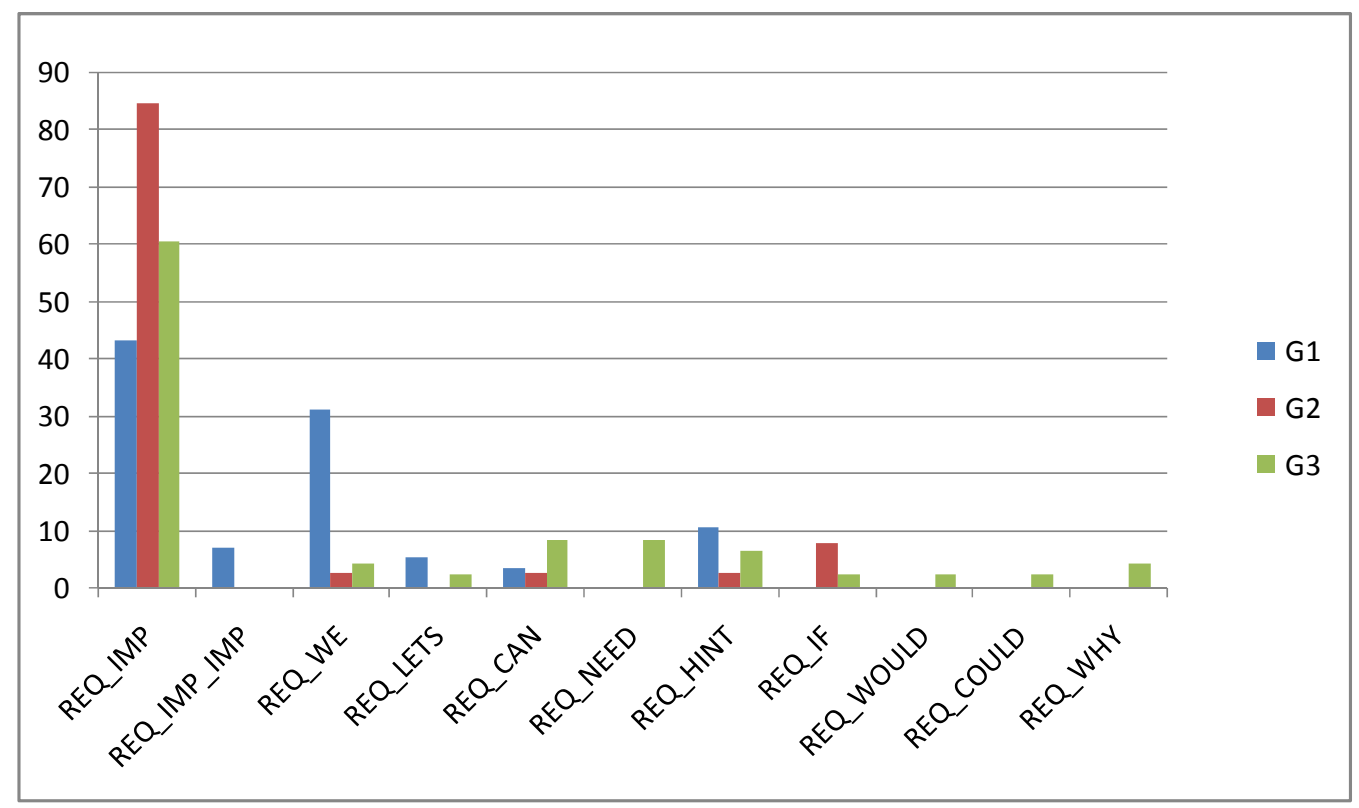

Figure 1. Distribution of requests across the three groups 
As the examples below show, by means of imperative requests, teachers directly tell students what they want them to do. The request in Excerpt 1 comes from G1 and occurs when the teacher asks one of the students to stick stickers on the board, as part of the task in which students are learning about numbers.

\section{Excerpt 1 (G1)}

Teacher (T): Vinga (name of the child), enganxa-li el gomets a les tres pomes. ("Come on (name of the child), stick the stickers on the [image of the] three apples".)

In Excerpt 2 (G2), the teacher has just finished telling a story to the kids. They are all sitting on the floor and the teacher is getting ready to set up another activity. However, some kids stand up.

Excerpt 2 (G2)

T: Please sit on the floor, (name of the kid).

In addition to imperatives, other request types were also used in the lessons, yet with a dissimilar distribution across the three groups (see Figure 1 above). The following section provides a description of the most preferred request types in each group.

\subsection{Teachers' Use of Requests per Groups}

\section{G1: L1 Catalan lessons}

In these lessons, the second most preferred type of request, after the imperatives, is requests with 'we' $(31 \%)$, followed by hints (10\%), impersonal requests (7\%), requests with 'let's' (5\%) and with 'can' (4\%) (see Figure 2).

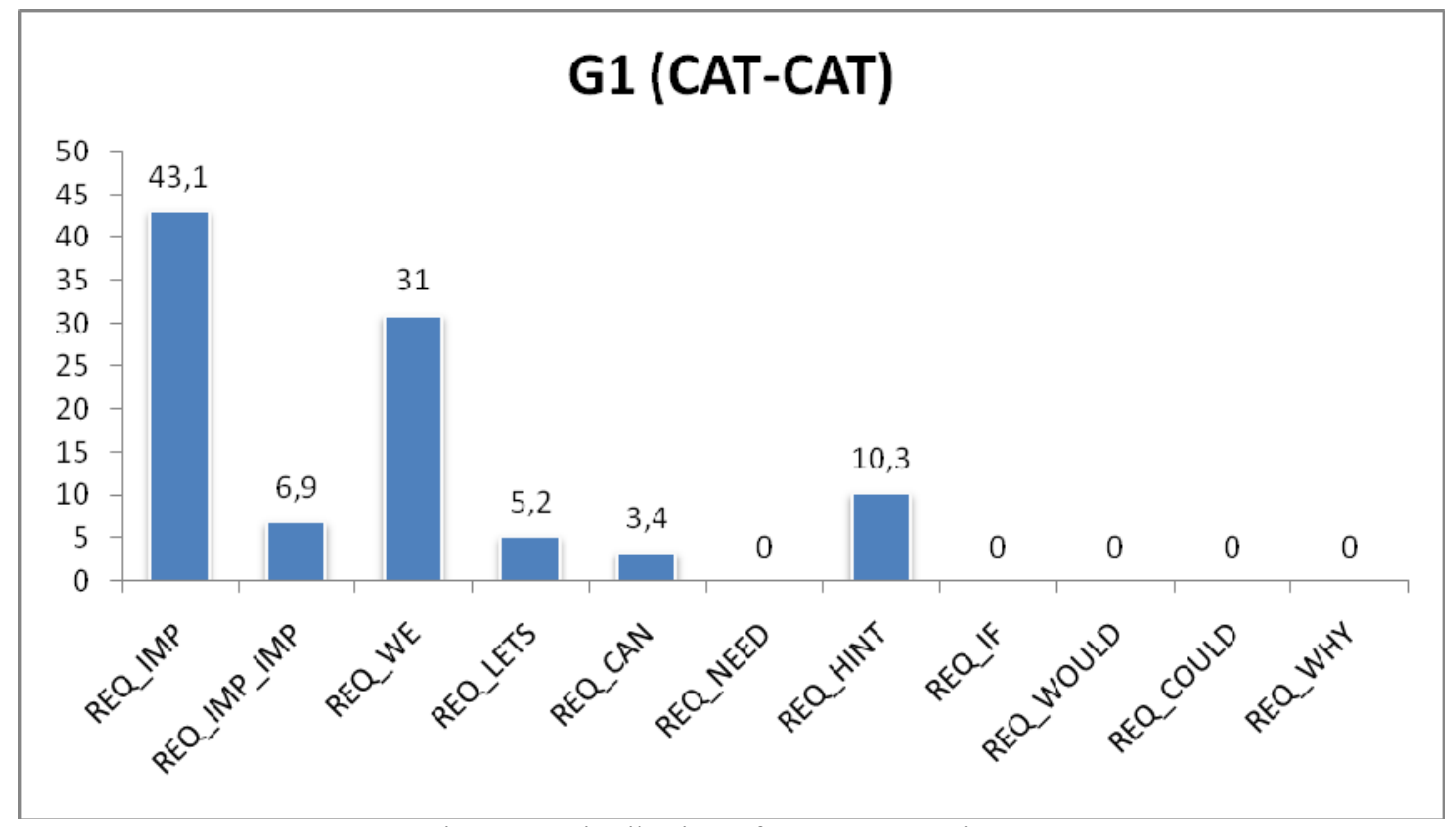

Figure 2. Distribution of request types in $\mathrm{G} 1$

Regarding requests with 'we', in this type the teachers aim at asking the students to do something but they also include themselves in the request. It is very similar to requests with 'let's', since it has the same pragmatic intention (e.g. asking the students to do something). For instance, in Excerpt 3 below, there are two students who are checking attendance, while the rest of the students are quiet. However, there is one boy who is talking, so the teacher uses a request with 'we' to ask the student to be quiet.

Excerpt 3 (G1)

T: (Name of the kid), ara estem en silenci. ("We keep silence now".)

A similar example is presented in Excerpt 4, in which students are doing an activity as a whole class, but some of them are trying to do it faster than others. The teacher uses a request with 'we' to ask them to stop doing it.

Excerpt 4 (G1)

T: No fem curses, ho fem bé. Vinga. ("we don't run, we do it well. Come on".)

Requests of this type are also used by EFL teachers and L1 English teachers, but at a very low rate (2\% and 4\%, respectively). 


\section{G2: EFL lessons}

As was mentioned earlier, imperatives are the predominant request strategy used by EFL teachers, which leads to a lower variety of request types as compared to G1. As can be seen in Figure 3, imperatives are followed by requests with 'if' ( $8 \%)$, 'we' (3\%) and 'can' (3\%), and hints (3\%).

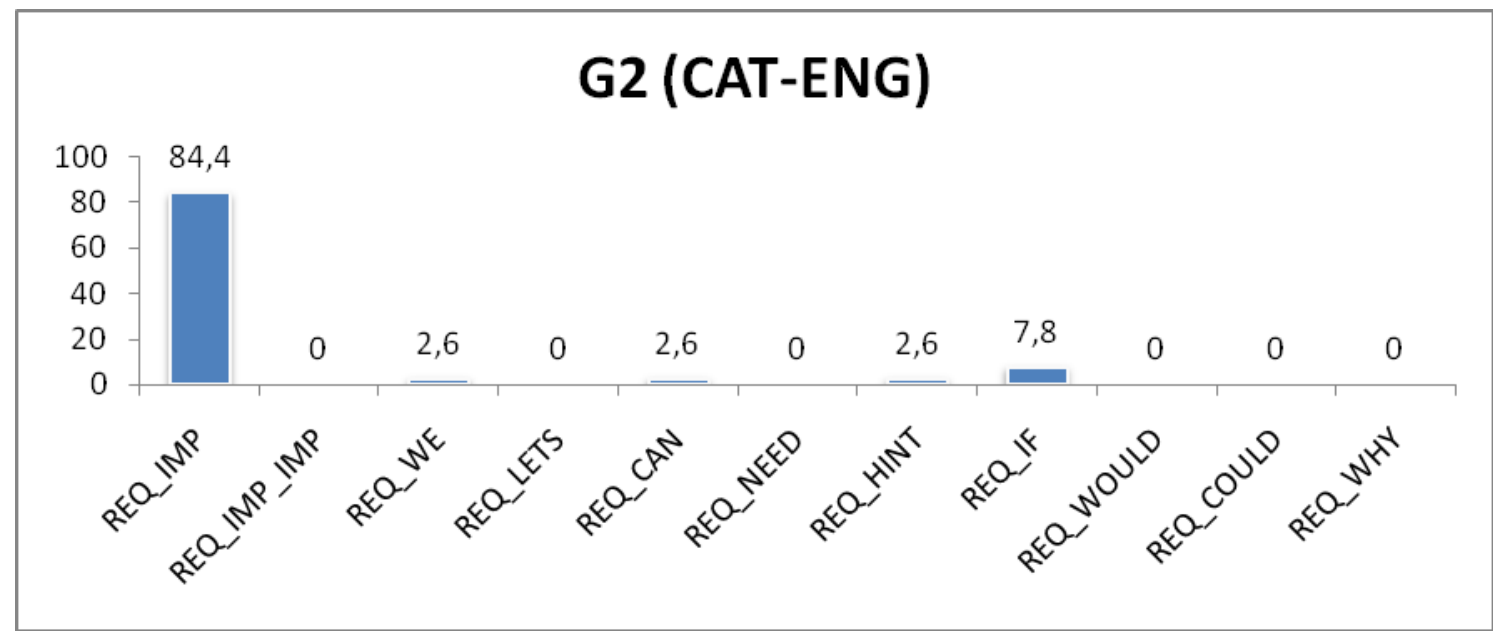

Figure 3. Distribution of requests in $\mathrm{G} 2$

For instance, in Excerpt 5 below, we can see that the teacher uses a request with 'if' when one of the students is sitting very far away from the rest of the kids, so she wants him to get closer.

Excerpt 5 (G2)

T: Listen, you can come closer if you want (showing with her hands).

Similarly, in Excerpt 6, we have the same type of request used in a similar context, in which there is one student who is not listening to the teacher, so she uses a request with 'if' strategy to ask the student to listen to her.

Excerpt 6 (G2)

T: If you listen, I will listen. If you don't, I won't.

\section{G3: L1 English lessons}

As for L1 English lessons, a much wider variety of requests strategies can be found. However, as mentioned earlier, imperatives are also the most preferred type of requests in this group. In fact, examples of practically all request types were found in this group, except for the impersonal requests. As Figure 4 shows, imperatives are followed by three most used strategies: requests with 'can' (8\%), 'need' (8\%), and hints (6\%).

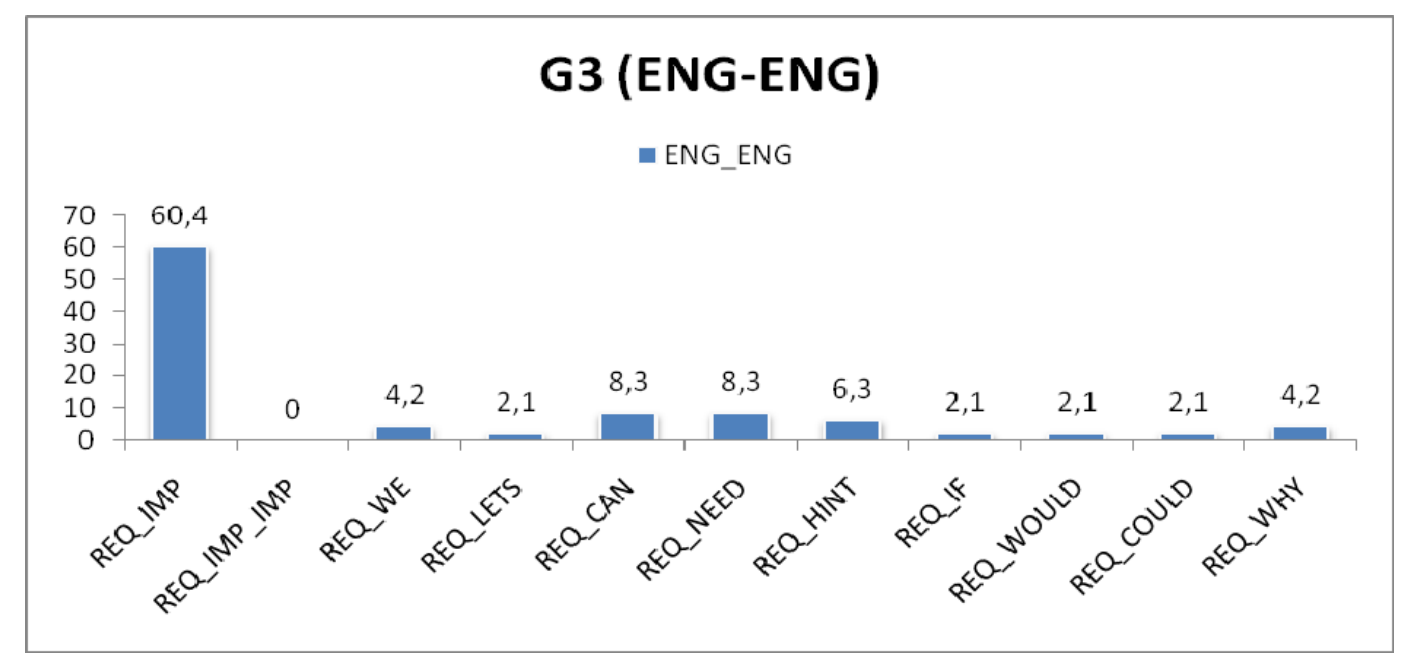

Figure 4. Distribution of requests in G3

As Excerpt 7 shows, we have an instance of the teacher using 'can' when asking a student to distribute paper sheets to her classmates. 


\section{Excerpt 7 (G3)}

T: (Name of the kid), can you give your friends one each?

An instance of a request with 'need' can be seen in Excerpt 8, in which the teacher is setting up an activity but the kids are not supposed to start doing it until the teacher has given the instructions, so by means of this request type she asks the students to wait.

Excerpt 8 (G3)

T: You need to learn to wait.

Similarly, Excerpt 9 shows a 'hint' request used by the teacher when the students are talking very loud while doing an activity: the teacher indirectly asks students to lower their voices.

Excerpt 9 (G3)

T: Shhh we are a bit loud here.

\subsection{Teachers' Interviews}

In the recall interviews, when being asked about their use of the most frequent request strategy (imperatives), both EFL, L1 Catalan and L1 English teachers (see excerpts 10 and 11) expressed a similar idea that using imperatives is an effective way to put their messages across with very young learners. According to the teachers, they are simple from both syntactic and pragmatic perspectives, which make them easy to understand, thus helping teachers get students do what they are asked to do.

\section{Excerpt 10}

We look for simple, shorter structures, so kids can act - so they can understand you easily ("hang up your coat" is shorter and more effective than "Could you hang up your coat, please?"). (Teacher 5/G2)

\section{Excerpt 11}

We have so many kids we need short/effective/direct expressions so they can do what they are supposed to. (Teacher 7/G1)

As for the second most preferred request type (requests with 'we') in G1, L1 Catalan teachers raised different issues. First of all, they claimed that they used 'we' because they did actually participate in the activities the kids were doing in class (see Excerpt 12). Another aspect that was mentioned was that using an imperative request shows some sort of closeness between the person who makes a request and the receiver, so the teachers used it as a strategy to shorten the distance between them and their students (see Excerpt 13). However, this seems to be their perception regarding young students in particular, since they also claimed that they would not use such strategy with older students, as can be seen in Excerpt 14. As the EFL teachers pointed out, the reason for doing this is the young learners' low proficiency level in English, which makes them simplify the L2 pragmatics and the L2 in general, as a way of adapting the language to the children's proficiency level.

Excerpt 12

Well, we are participating in one way or another. (Teacher $1 / \mathrm{G} 1$ )

\section{Excerpt 13}

Yes, when you include yourself, it seems closer to the person you are talking to. For example, if you say "go have breakfast" "desayunad" it sounds more distant.(Teacher 3/G1)

\section{Excerpt 14}

We use "we" a lot because they are young. We would never use it with older students (e.g. high school students). (Teacher $5 / \mathrm{G} 1$ )

\section{Discussion}

This study aimed to explore how requests are displayed by pre-primary teachers in L1 Catalan, L1 English and EFL classrooms. The findings show that when comparing requests used across the three groups, a common pattern can be traced in the three languages: imperative requests seemed to be the most preferred type of request in all groups, independently of the language used. However, a wider requestive repertoire was identified in G1 (L1 Catalan) and G3 (L1 English) than in G2 (EFL), in which imperatives were used with the highest frequency. Regarding such use of imperatives, as the teachers from the three groups mentioned during the recall interviews, they are simple structures, both in terms of their syntactic structure and pragmatic function, and therefore, an effective strategy to make young students understand and perform the actions they have been asked to do. According to the interviewed teachers, this is the reason why they tend to use such request strategy in their classrooms. This finding goes in line with Carrell (1981), who found that direct requests were easily understood by very young children while indirectness was better understood as students' age and language competence 
increased.

Regarding the use of imperative requests in G2 by the EFL teachers, our findings corroborate previous research which shows that FL teachers tend to be pragmatically more direct than L1 teachers which might be due to young learners' low L2 competency level (Falsgraf \& Majors, 1995; Dalton-Puffer, 2007). However, as Nikula (2002) pointed out, this may have an effect on the pragmatic exposure learners get, which might imply that FL classrooms offer a narrow pragmatic repertoire as compared to L1 classrooms. In the study by Safont (2013), the participant, who was the same age as the children of the present study, showed development from direct to indirect requests in Catalan and Spanish, but according to the findings, when English was introduced, indirect requests in Catalan and Spanish increased. In the study it is claimed that exposure to the English indirect requests promoted the use of indirect requests in Catalan and Spanish as well. This is a common effect of cross-linguistic influence in multilingual settings, in which it is not the L1 which influences the L2 or L3, but any language that is learned may influence previously learned languages. In the study just mentioned, such influence was considered as positive, since it fostered the use of indirect strategies in his L1s, and probably an increase in his pragmatic awareness and perception. Therefore, exposing children to a wide variety of pragmatic strategies in the EFL classroom (as it is done in the L1) should be promoted in the FL class since it seems to have positive effects on both their L1 and L2 pragmatic development.

From a pragmatic socialization point of view, teachers, as well as parents and caregivers, are 'expert members of the community' (Blum-Kulka 1997). As 'expert members', teachers act as pragmatic models for very young students, by providing them with politeness norms and a variety of pragmatic strategies. As our study shows, pre-primary teachers tend to do so particularly in the L1 contexts, as opposed to the EFL classrooms. As discussed above, the EFL teachers in our study seem to be aware of the possible constraints that the learners' proficiency level might have on their learning experiences in the classroom which leads teachers to use a much less varied set of pragmatic strategies in their lessons. However, as previously mentioned, the learners' proficiency should not be seen as a constraint, since learners at this age may benefit from such pragmatic exposure, not only in their L2 but also in their L1.

\section{Conclusion}

This exploratory study aimed to get insights into the kind of pragmatic input students are exposed to in classroom contexts at very early stages of language acquisition, in both their L1 and the L2. Results show that L1 classrooms provide a wider pragmatic repertoire than FL classrooms, and that imperative requests are a common strategy used by the teachers of the three groups.

This study, though, has some limitations: first, the low number of video-recorded sessions and the number of teachers who participated in the study; second, the analysis of only one speech act. Future studies should include a higher number of teachers and recorded sessions. Moreover, future research should also explore other pragmatic moves that are used in pre-primary classrooms. Another interesting line of future inquiry is how young learners' process pragmatic input provided by pre-primary EFL teachers, in order to better understand how EFL teachers can expose young learners to a wider variety of pragmatic strategies in the L2 as well.

To conclude, this study emphasizes the need to raise (L1 and EFL) teachers' awareness about the effect their language use might have on the development of learners' pragmatic competence both in the L1 and the L2. Pedagogical proposals aimed at teaching (both explicitly and implicitly) pragmatics in pre-primary education that contain a wider variety of pragmatic strategies will undoubtably have a positive effect on young learners' pragmatic competence.

\section{References}

Alcón-Soler, E. (2005). Does instruction work for learning pragmatics in the EFL context? System, 33(3), 417-435. https://doi.org/10.1016/j.system.2005.06.005

Bardovi - Harlig, K. (2013). Developing $\quad$ L2 pragmatics. Language Learning, 63, 68-86. https://doi.org/10.1111/j.1467-9922.2012.00738.x

Bialystok, E. (1993). Symbolic representation and attentional control in pragmatic competence. In G. Kasper \& S. Blum-Kulka (Eds.), Interlanguage Pragmatics (pp. 43-59). New York: Oxford University Press.

Blum-Kulka, S. (1997). Discourse Pragmatics. In T.A. van Dijk (Ed.), Discourse as Social Interaction (pp. 38-63). London: Sage.

Blum-Kulka, S. \& Olshtain, E. (1984). Requests and apologies: a cross-cultural study of speech act realization patterns (CCSARP). Applied Linguistics, 5, 196-213. https://doi.org/10.1093/applin/5.3.196

Carrell, P. L. (1981). Children's understanding of indirect requests: Comparing child and adult comprehension. Journal of Child Language, 8(2), 329-345. https://doi.org/10.1017/S0305000900003226 
Clark, H.H. (1979). Responding to indirect speech acts. Cognitive Psychology, 11, 430-477. https://doi.org/10.1016/0010-0285(79)90020-3

Curell, H. 2011. Politeness and cultural styles of speaking. In L.Payrató \& J.M. Cots (Eds.) The Pragmatics of Catalan. Berlin: Mouton de Gruyter, 273-309. https://doi.org/10.1515/9783110238693.273

Dalton-Puffer, C. (2007). Discourse in Content and Language Integrated Learning (CLIL) Classrooms (Vol. 20). John Benjamins Publishing. https://doi.org/10.1075/1llt.20

Ellis, R. (1992). Learning to communicate in the classroom: a study of two language learners' requests. Studies in Second Language Acquisition, 14(1), 1-23. https://doi.org/10.1017/S0272263100010445

Falsgraf, C., \& Majors, D. (1995). Implicit culture in Japanese immersion classroom discourse. The Journal of the Association of Teachers of Japanese, 29(2), 1-21. https://doi.org/10.2307/489587

González-Lloret, M. (2019). TBLT and L2 Pragmatics. In N. Taguchi (Ed.), Routledge Handbook of Second Language Acquisition and Pragmatics (pp. 338-353). New York, NY: Routledge. https://doi.org/10.1093/applin/amz031

Grief, E.B. \& Gleason, J.B. (1980). Hi, thanks, and goodbye: More routine information. Language in Society, 9 , 159-166. https://doi.org/10.1017/S0047404500008034

Kasper, G., \& Rose, K.R. (2002). Pragmatic Development in a Second Language. Oxford: Blackwell.

Ladegaard, H. J. (2004). Politeness in young children's speech: context, peer group influence and pragmatic competence. Journal of Pragmatics, 36(11), 2003-2022. https://doi.org/10.1016/j.pragma.2003.11.008

Li, D. (2008). Pragmatic socialization. In P. Duff \& N. H. Hornberger (Eds.), Encyclopedia of Language and Education, (1-13). Springer. https://doi.org/10.1002/9781405198431.wbeal0931

Lörscher, W., \& Schulze, R. (1988). On polite and foreign language classroom discourse. IRAL: International Review of Applied Linguistics in Language Teaching, 26(3), 183-199. https://doi.org/10.1515/iral.1988.26.3.183

Martínez-Flor, A., \& Fernández-Guerra, A. B. F. (2002). Coursebooks and films in foreing language teaching: a pragmatic approach. Sell: Studies in English Language and Linguistics, 4,181-206.

Martínez-Flor, A. \& Usó-Juan, E. (2011). Research methodologies in pragmatics: Eliciting refusals to requests. ELIA, 11, 47-87.

Nikula, T. (2008). Learning pragmatics in content-based classrooms. In E. Alcón \& A. Martínez-Flor (Eds.), Investigating Pragmatics in Foreign Language Learning, Teaching and Testing (pp. 94-113). Clevedon: Multilingual Matters. https://doi.org/10.21832/9781847690869

Nikula, T. (2002). Teacher talk reflecting pragmatic awareness. Pragmatics. Quarterly Publication of the International Pragmatics Association (IPrA), 12(4), 447-467. https://doi.org/10.1075/prag.12.4.03nik

Ochs, E. (1990). Indexicality and socialization. In J. Stigler, R. Shweder, \& G. Herdt (Eds.). Cultural Psychology. Essays on Comparative Human Development, (pp. 287-308). Cambridge University Press, Cambridge. https://doi.org/10.1017/CBO9781139173728.009

Ohta, A. S. (2001). Second Language Acquisition Processes in the Classroom: Learning Japanese. Mahwah, NJ: Lawrence Erlbaum. https://doi.org/10.4324/9781410604712

O'Neill, M., \& Casanovas, M. (1997). The use of imperative in Catalan and English. Advertisements: a pragmatic analysis. Bells: Barcelona English Language and Literature Studies, 8, 261-280.

Pérez i Parent, M. (2002). The production of requests by Catalan learners of English: Situational and proficiency level effects. Atlantis, 147-168.

Safont-Jordà, M. P. (2013). Early stages of trilingual pragmatic development. A longitudinal study of requests in $\begin{array}{llll}\text { Catalan, Spanish and English. Journal of pragmatics, 59, } & \text { 68-80. }\end{array}$ https://doi.org/10.1016/j.pragma.2013.01.007

Searle, J. R. (1969). Speech Acts: an Essay in the Philosophy of Language. Cambridge: Cambridge University Press. https://doi.org/10.1017/CBO9781139173438

Taguchi, N. (2015). Instructed pragmatics at a glance: Where instructional studies were, are, and should be going. Language Teaching, 48(1), 1-50. https://doi.org/10.1017/S0261444814000263

Taguchi, N. (2011). Teaching pragmatics: Trends and issues. Annual Review of Applied Linguistics, 31, 289-310. https://doi.org/10.1017/S0267190511000018

Tateyama, Y. (2019). Pragmatics in a language classroom. In N. Taguchi (Ed.), The Routledge Handbook of Second Language Acquisition and Pragmatics (pp. 400-412). New York, NY: Routledge. https://doi.org/10.1093/applin/amz031 
Tateyama, Y., \& Kasper, G. (2008). Talking with a classroom guest: Opportunities for learning Japanese pragmatics. In Alcón, E., \& Martínez-Flor, A. (Eds.), Investigating Pragmatics in Foreign Language Learning, Teaching and Testing, (pp. 45-71). Clevedon: Multilingual Matters. https://doi.org/10.1016/j.pragma.2009.12.007

\section{Note}

Note 1. P3 corresponds to the preschool period when children are 3 years old. P4 and P5 stand for Junior and Senior Kindergarten at the ages of 4 and 5.

\section{Appendix 1}

\section{Teachers' interview questions}

1) Why do you use imperatives? We want kids to avoid imperatives, to be polite, but then, we use imperatives.

2) The 'Please' "myth" - in the lessons that were video-recorded, 12 'please' were found in Catalan L1/ English L2 classes, vs. 1 'please' in the English native speaker classes. What do you think about this type of requests?

3) How do think you teach kids pragmatics? Politeness norms?

4) I have noticed you use "we" a lot (e.g. in Catalan "ara anem a dibuxar") even though we don't do these activities ourselves.

5) One thing that always surprises me is the way people refer to you at university - as it varies depending on their culture (locals normally call me by my name, while foreign students often use Dr or Miss). These are cultural norms. Society changes and this is reflected in the way we speak.

6) What other politeness areas/aspects do you think are important? E.g. thanking, apologizing, etc. - in which situations would you comment on these aspects explicitly?

7) Learning to socialize involves learning certain linguistic routines (e.g. good morning) -this makes us more human, more polite, it connects us. It is highly important for kids this age to socialize; values, culture and language are related. How do you do it in class?

8) What is the progression in terms of politeness from P3 to P5?

9) I have noticed that in P5, imperatives are not used so much. Instead, teachers adapt and they use more varied strategies. Why do you think you do that?

10) I once read about an experiment in which kids were given a present. If parents were there, they were prompted somehow to say "thank you". When parents were not there, some kids did not even look at the person who gave them the present. Adults act as role models. What do you think about this?

\section{Appendix 2}

Request Strategies (Blum-Kulka \& Olshtain, 1989: 202)

\begin{tabular}{ll}
\hline Type & Example \\
\hline Mood derivable & Leave me alone \\
Explicit performative & I am asking you to dress up the mess \\
Hedge performative & I would like to ask you to give ... \\
Locution derivable & Madam, you'll have to move your car \\
Scope stating & I wish you'd stop bothering me \\
Suggestory formulae & So, why don't you clean ... \\
Reference to preparatory conditions & Could you clean up the kitchen, please? \\
Strong hints & You've left the kitchen in a night mess \\
Mild hints & I am a nun \\
\hline
\end{tabular}

\section{Copyrights}

Copyright for this article is retained by the author(s), with first publication rights granted to the journal.

This is an open-access article distributed under the terms and conditions of the Creative Commons Attribution license (http://creativecommons.org/licenses/by/4.0/). 